\title{
Ecossocialismo indoamericano
}

\section{Indoamerican Ecosocialism}

\author{
Efendy Emiliano Maldonado \\ Mestrando em Teoria, Filosofia e História do Direito (UFSC) \\ eemilianomb@gmail.com
}

\begin{abstract}
Resumo: O artigo propõe uma análise dos processos constituintes promovidos pelos povos boliviano e equatoriano na última década. Em busca disso, serão abordadas as particularidades desses processos sob o prisma das Teorias Críticas, a partir dos elementos trazidos pelo marxismo de Mariátegui, o ecossocialismo de Michel Löwy e o descolonialismo de Enrique Dussel, no escopo de contribuir na construção de Ecossocialismo Indoamericano plasmado numa Epistemologia do Sul, que fortaleça reflexões comprometidas com as transformações sociopolíticas da América Latina, especialmente, aquelas vinculadas à perspectiva dos movimentos indígenas e camponeses. Resumidamente, pode-se afirmar que da análise desses processos constituintes emerge a possibilidade de uma transformação significativa da tradição jurídico-política moderna, sobretudo, no que se refere à participação dos povos indígenas e à influência marcante das suas perspectivas contra-hegemônicas na elaboração dos respectivos textos constitucionais, especialmente, no tocante à proteção dada aos bens comuns da humanidade e ao reconhecimento e defesa dos seus territórios.
\end{abstract}

Palavras-chave: América Latina. Processos constituintes. Bolívia. Equador. Ecossocialismo.

\begin{abstract}
The article proposes an analysis of the constituent processes promoted by the Bolivian and Ecuadorian people in the last decade. In pursuit of this, we will discuss the particularities of these processes from the perspective of Critical Theories, from the elements brought by Mariátegui Marxism, the ecosocialism from Michel Lowy and Enrique Dussel's descolonialism in scope to contribute in building Indoamerican Ecosocialism enshrined in South Epistemology, to strengthening reflections committed to the socio-political transformations in Latin America, especially those related to the perspective of indigenous and peasant movements. Briefly, it can be stated that the analysis of these constituent processes emerges the possibility of a significant transformation of modern legal and political tradition, especially as regards the participation of indigenous peoples and the strong influence of their counter-hegemonic perspectives in the preparation of respective constitutional texts, especially with regard to the protection given to the common property of humanity and the recognition and defense of their territories.
\end{abstract}

Keywords: Latin America. Constituent processes. Bolivia. Ecuador. Ecosocialism.

Originais recebidos em: 24/03/2014

Aceito para publicação em: 27/06/2014

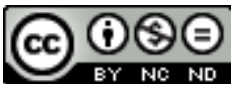

Este trabalho está licenciado sob uma Licença Creative Commons Atribuição-Uso NãoComercial-Vedada a criação de obras derivadas 3.0 Unported License. 


\section{Considerações iniciais para uma reflexão ecossocialista indoamericana sobre as Constituintes Equatoriana e Boliviana}

Neste trabalho pretende-se aprofundar o debate sobre os processos constituintes ocorridos na última década na América Latina, isto é, sobre os processos políticos promovidos pelos povos boliviano e equatoriano. Em busca disso, utilizaremos as proposições das correntes teóricas ecossocialistas e decoloniais, as quais buscam superar as correntes do marxismo ortodoxo de viés eurocêntrico e desenvolvimentista, a fim de realizar uma análise crítica dos processos constituintes boliviano e equatoriano, investigando de que forma as pautas, demandas e necessidades jurídico-políticas dos movimentos sociais contra-hegemônicos, especialmente, aquelas vinculadas à perspectiva dos movimentos indígenas e camponeses, foram incorporadas às novas Constituições.

Assim, retrataremos o papel e influência das lutas dessas organizações populares, sobretudo, no que se refere às mudanças paradigmáticas incorporadas às novas Constituições desses países latino-americanos. Contudo, tendo em vista o momento atual da investigação, pretende-se apresentar apenas o início de uma pesquisa bibliográfica de caráter qualitativo vinculada à essas temática.

Nos limites deste trabalho, abordaremos as particularidades desses processos constituintes sob o prisma das Teorias Críticas, em especial, dos elementos trazidos pelo marxismo de Mariátegui, o ecossocialismo de Michel Löwy e o decolonialismo de Enrique Dussel, no intuito de contribuir no longo caminho a ser percorrido para a construção de Ecossocialismo Indoamericano plasmado numa Epistemologia do Sul, que fortaleça reflexões comprometidas com as transformações sociopolíticas da América Latina.

Resumidamente, pode-se afirmar que da análise dos novos textos constitucionais equatoriano e boliviano emerge a possibilidade de um processo de ruptura significativa com a tradição jurídica moderna e com o caráter elitista da cultura constitucional latinoamericana, sobretudo no que se refere à participação social dos povos indígenas nos processos jurídico-políticos constituintes, assim como sobre a influência marcante das suas pautas e perspectivas contra-hegemônicas na elaboração dos respectivos textos constitucionais desses países e pela incorporação e reconhecimento de um projeto alternativo ao capitalismo, no qual a cosmovisão andino-amazônica desses povos 
ressalta uma nova relação entre o ser humano/natureza, sobretudo, no tocante à proteção dada por esses novos textos constitucionais aos bens comuns da humanidade e ao reconhecimento e defesa dos seus territórios.

No entanto, para compreender esses novos textos, torna-se fundamental estudar aprofundadamente os processos constituintes ocorridos nos últimos anos em Nuestra América, em especial na Bolívia e no Equador, pois eles estão marcados pela intensificação das lutas e pautas anti-sistêmicas e/ou contra-hegemônicas dos movimentos sociais indígenas e camponeses desses países. Brevemente poderíamos afirmar que tal aspecto decorre, principalmente, da excessiva e violenta acumulação primitiva dos bens naturais e, por conseguinte, do capital, por parte de setores da "burguesia nacional" e dos conglomerados transnacionais, que nos últimos anos aprimoram a implementação do projeto econômico-político expropriatório neoliberal.

Nesse sentido, os processos constituintes levados a cabo nos últimos anos nesses países são fruto de um elevado número de necessidades sociais insatisfeitas ao longo dos anos, decorrentes da ampliação das desigualdades sociais e de mecanismos de exclusão que propiciaram um ambiente de profunda instabilidade sociopolítica nesses países.

Assim, pretende-se abordar os aspectos transformadores observados nas lutas sociais ocorridas ao longo desses processos constituintes, dando maior atenção àquelas que promoveram possíveis rupturas com a tradição desenvolvimentista da modernidade e os resultados e as incidências provocadas por esse novo marco jurídico-político na relação ser humano/natureza, sobretudo, a partir das mudanças na proteção dada aos bens comuns da humanidade, aos territórios indígenas e ao modelo de desenvolvimento, as quais aparentemente podem ser capazes de propiciar um projeto de transição - no plano econômico, político, cultural, etc. - que supere o capitalismo.

\section{Socialismo Indoamericano}

Como referimos anteriormente, o presente estudo busca analisar os processos constituintes equatoriano e boliviano sob o prisma das proposições teóricas de Mariátegui, Michel Löwy e Enrique Dussel, pois entendemos que esses três autores tem caracterizado e projetado uma vertente sumamente criativa e heterodoxa do pensamento político marxiano, fincada na necessidade de transformação das realidades sociais 
concretas e nas especificidades histórico-culturais da formação capitalista no continente latino-americano.

Nesse sentido, começaremos por abordar a proposta teórica do peruano José Carlos Mariátegui, considerado por muitos um dos primeiros pensadores a aplicar a teoria e o método marxista à realidade sul-americana, não simplesmente mimetizar interpretações eurocêntricas. Utilizaremos como base a sua obra "Sete Ensaios de Interpretação da Realidade Peruana"1.e, também, a coletânea "Por um socialismo indoamericano" ${ }^{2}$, cuja seleção de ensaios e artigos jornalísticos, sintetiza parte relevante das suas reflexões sócio-políticas e das proposições que intitulam este trabalho.

Segundo Löwy, o autor peruano (...) é não somente o mais importante e inventivo dos marxistas latino-americanos, mas também um pensador cuja obra, por sua força e originalidade, tem um significado universal (MARIÁTEGUI, 2005, p. 7). Tal constatação torna-se fundamental, pois não se pretende aqui pensar e/ou fragmentar o marxismo a uma determinada região do mundo, reconhecemos o caráter universal e internacionalista das reflexões e proposições marxianas, mas, sobretudo, compreendemos que o seu método deve ser aplicado observando a realidade e as peculiaridades do modelo econômico, social, político e cultural existente no continente, ou seja, concreta e historicamente situados. Sobre isso, o próprio autor peruano aduz que:

\begin{abstract}
O socialismo não é, certamente, uma doutrina indo-americana. Mas nenhuma doutrina, nenhum sistema contemporâneo não é nem pode sê-lo. E o socialismo, embora tenha nascido na Europa, tal como o capitalismo, tampouco é específica ou particularmente europeu. É u m movimento mundia, a que não se subtrai nenhum dos países que se movem dentro da órbita da civilização ocidental. Esta civilização conduz, com uma força e com meios de nenhuma civilização dispôs, à universalidade. A Indo-América, nesta ordem mundial, pode e deve ter individualidade e estilo, mas não uma cultura nem um destino particulares. (MARIÁTEGUI, 2005, p. 120).
\end{abstract}

Feitas essas considerações preliminares, entre os aspectos que interessam retomar da obra do marxista peruano são a sua crítica ao positivismo, ortodoxismo e desenvolvimentismo de certas vertentes economicistas do marxismo, em especial, o stalinismo que começava a hegemonizar os partidos comunistas no continente, buscando resgatar o caráter mítico e utópico necessária para pensar um projeto verdadeiramente revolucionário, isto é, socialista.

\footnotetext{
${ }^{1}$ Utilizaremos aqui a obra brasileira: MARIATÉGUI, José Carlos. Sete ensaios de interpretação da realidade peruana. Trad: de Felipe José Lindoso. $1^{a}$ ed. São Paulo: Expressão Popular/Clacso, 2008.

${ }^{2}$ MARIATÉGUI, José Carlos. Por um socialismo indo-americano: ensaios escolhidos. Seleção e Introdução de Michel Löwy; trad. Luiz Sérgio Henriques. Rio de Janeiro: Editora UFRJ, 2005.
}

Em Debat: Rev. Dig., ISSNe 1980-3532, Florianópolis, n. 9, p. 56-73, jan-jun, 2013. 
A própria palavra Revolução, nesta América de pequenas revoluções, prestase a muitos equívocos. Temos de reivindicá-la rigorosa e intransigentemente. Temos de restituir-lhe seu sentido estrito e cabal. A revolução latinoamericana será uma etapa, uma fase da revolução mundial, nada mais, nada menos. Será, pura e simplesmente, a revolução socialista . A esta palavra acrescentem, segundo os casos, todos os adjetivos que quiserem: "antiimperialista", "agrarista", "nacionalista-revolucionária". O socialismo se supõe, os antecede, abrange-os a todos. (MARIÁTEGUI, 2005, p. 119).

A crítica a ideia de progresso e o desenvolvimentismo plasmado pelo cientificismo economicista de setores da esquerda latino-americana continua atual e vigente. A perspectiva etapista do projeto dos partidos comunistas, que defendiam a necessidade de uma etapa de desenvolvimento capitalista e, por conseguinte, a necessidade de uma aliança com a(s) "burguesia nacional" para realizar primeiramente reformas democráticas e econômicas que possibilitem um processo de industrialização que "nos retire do atraso", parece estar na ordem do dia dos partidos de esquerda que chegaram ao poder em nosso continente e que dia a dia vem implantando projetos desenvolvimentistas em aliança com setores da burguesia e das transnacionais que violam os direitos coletivos dos povos e comunidades tradicionais e que desrespeitam a legislação socioambiental, no escopo de maximizar os lucros do capital e extrair o que resta de minério e matérias primas em nosso solo e florestas.

Mariátegui, ao contrário de boa parte dos intelectuais que mimetizavam as diretrizes de Moscou, criticou o desenvolvimentismo, enfatizou a necessidade de pensar um projeto revolucionário socialista e percebeu a riqueza e potencialidade das comunidades indígena-campesinas para uma transição que supere o capitalismo.

Nessas comunidades (Ayllus) remanescentes do período incaico e que resistiram à implantação sanguinária da colônia e do capitalismo, há formas de organicidade riquíssimas em valores de solidariedade, justiça social, divisão igualitária do trabalho e propriedade comum da terra, senão vejamos o seguinte trecho:

As comunidades baseiam-se na propriedade comum das terras em que vivem e cultivam e preservam, por pactos e por laços de consangüinidade que unem entre si as diversas famílias que formam o ayllu. (...) As terras comunais pertencem a todo o ayllu, ou seja, ao conjunto de famílias que formam a comunidade. (...)Mas o espírito coletivista do indígena não se revela apenas na existência das comunidades. O costume secular da minka subsiste nos territórios do Peru, da Bolívia, do Equador e do Chile (...) O IV Congresso da IC ressaltou mais de uma vez a possibilidade, para povos de economia rudimentar, de iniciar diretamente uma organização econômica coletiva, sem sofrer a longa evolução pela qual outros povos passaram. Acreditamos que, entre as povoações "atrasadas", nenhuma como a população indígena incásica reúne condições tão favoráveis para que o comunismo agrário primitivo, subsistente em estruturas concretas em em um profundo espírito coletivista, se transforme, sob a hegemonia da classe proletária, em uma base mais sólida da sociedade coletivista pregada pelo comunismo marxista.

Em Debat: Rev. Dig., ISSNe 1980-3532, Florianópolis, n. 9, p. 56-73, jan-jun, 2013. 
(Mariátegui, 2005, 142-144).

Segundo o autor, não se trata de um retorno ao passado, proposta típica de um saudosismo idealista, mas sim de a partir da realidade e riqueza desse tipo de organização comunal existente em boa parte dos países andinos instigar e promover modos de resistência e autodeterminação para a consolidação de um projeto econômicopolítico de caráter socialista.

Só o movimento revolucionário classista das massas indígenas exploradas poderá lhes permitir dar um sentido real à libertação de sua raça da exploração, favorecendo as possibilidades de autodeterminação política. $\mathrm{Na}$ maioria dos casos, o problema indígena identifica-se com o problema da terra. A ignorância, o atraso a miséria dos indígenas são apenas consequência de sua servidão. (Mariátegui. In: Löwy, 2006, p. 112).

Nesse aspecto, Mariátegui demonstra que o movimento comunista mundial, deve reformular e adequar as suas interpretações sobre o papel do campesinato para poder compreender e organizar adequadamente uma transição revolucionária na América Latina, ou seja, deve-se recolocar o problema indígena e perceber a sua importância em determinados países, mas sempre dentro de uma perspectiva classista. Nesse sentido, não se trata de puro indigenismo, pelo contrário, trata-se de um socialismo indoamericano, situado concretamente na histórica formação econômicopolítica e nas peculiaridades sócio-culturais do nosso continente.

Por minha conta, o que afirmo é que, em relação à convergência ou articulação de "indigenismo" e socialismo, ninguém que considere o conteúdo e a essência das coisas pode surpreender-se. O socialismo ordena e define as reivindicações das massas, da classe trabalhadora. E, no Peru, as massas - a classe trabalhadora - são indígenas na proporção de quatro quintos. Nosso socialismo, pois, não seria peruano - sequer seria socialismo - se não se solidarizasse, primeiramente, com as reivindicações indígenas. (MARIÁTEGUI, 2005, p. 110).

Desse modo, não se trata de retirar o papel do proletariado na luta de classes e tornar o problema étnico como eixo central, pelo contrário, trata-se de redimensionar o problema indígena para uma escala social e classista, isto é, a nova colocação consiste em procurar o problema indígena no problema da terra (MARIÁTEGUI, 2008, p. 61), promovendo uma necessária e fundamental aliança proletária e camponesa, na qual a resistente cultura indígena potencializa e possibilita os processos de coletivização e solidariedade fundamentais à construção de uma sociedade comunista.

Questionar a visão ortodoxa que não reconhecia a importância crucial do campesinato-indígena num projeto revolucionário no continente, significa, portanto, pensá-lo de forma conexa à problemática concreta da origem e formação capitalista na América Latina. Recolocar a problemática indígena, unindo-a a superação da divisão 
desigual do trabalho e da constituição da propriedade privada como alicerce das relações de produção (proprietário-trabalhador), significa, portanto, superar os gamonales (latifúndio) e sua relação exploratória de servidão, bem como, garantir e promover a existência de terras comunais, nas quais o coletivismo prevaleça e se aperfeiçoe gerando cooperativas de produção e formas de autogestão capazes de minar a organização hierarquizada e centralizada do Estado capitalista.

A dimensão crucial do problema da terra para a transformação da sociedade latino-americana e a superação do capitalismo na região está intimamente associada à questão indígena e ao resgate da instituição mais característica da sua civilização, a comunidade (MARIÁTEGUI, 2005, p. 138), pois a práxis desse tipo de organicidade comunal existente a centenas de anos, comprova a hipótese comunista, isto é, a possibilidade que a humanidade tem de organizar a vida social, sem a exploração do trabalho e, sobretudo, sem a propriedade privada dos meios de produção, mas sim como na definição marxiana de uma comunidade de produtores livres associados. Sobre isso, o Amauta $^{3}$ refere que:

Numa raça de costumes e de alma agrárias, como a raça indígena, esta privação constitui uma causa de dissolução material e moral. A terra sempre foi a alegria do índio. O índio casou-se com a terra. Sente que "a vida vem da terra" e volta à terra. Por isso, o índio pode ser indiferente a tudo, menos a posse da terra, que suas mãos e seus esforços lavram e fecundam laboriosamente. (MARIATÉGUI, 2005, p. 86)

Desse modo, buscar uma solução para o problema agrário, além de significar uma ruptura com o eixo central do sistema capitalista (propriedade privada dos meios de produção), possibilita que os povos indígenas mantenham viva a sua cosmovisão andino-amazônica que possui outro tipo de relação com a natureza, significa também garantir que seus territórios não entrem na especulação do mercado imobiliário e permaneçam organizado de forma comunal, significa, portanto, romper com a perspectiva individualista capitalista e plasmar uma forma de organização social distinta.

No entanto, deve-se deixar claro que para Mariátegui essa possibilidade só viria através da organização política, ou seja, de uma aliança proletária-campesina, onde os indígenas (que constituíam à época quatro quintos da população peruana) seriam os verdadeiros protagonistas, pois nas palavras do marxista peruano a Solução do

\footnotetext{
3 Na língua quéchua Amauta (Amawtay) significa sábio e/ou mestre, no período incaico eram os responsáveis por passar o conhecimento ancestral nas casas do saber. No caso específico, José Carlos Mariátegui, ficou conhecido por esse apelido, pois fundou e dirigiu a revista Amauta e tornou-se famoso nos círculos da intelectualidade e da política peruana pelo resgate da sabedoria incaica.
} 
problema do problema do Índio tem de ser uma solução social. Seus realizadores devem ser os próprios índios. (MARIATÉGUI, 2005, p. 88).

\section{Ecossocialismo}

Esboçado os principais elementos teóricos que incorporamos da obra de Mariátegui e a partir da qual inserimos a nossa interpretação sobre a realidade latinoamericana, passemos ao segundo autor que nos propomos a abordar, isto é, Michel Löwy, o qual foi um dos principais divulgadores do pensamento de Mariátegui em Português, sendo responsável por organizar e selecionar os ensaios que compõe o livro que inspirou o título deste trabalho.

Nosso interesse em utilizar esse autor se dá porque, além dos aportes de Löwy sobre o pensamento do Amauta, o marxista franco-brasileiro é o responsável por fortalecer uma das tendências mais interessantes do pensamento marxiano atual, já que vem trabalhando a temática ecológica desde uma perspectiva crítica e comprometida com a luta de classes e a superação da ordem capitalista.

Trata-se de uma vertente que se autodenomina ecossocialista, a qual nas palavras do referido autor é:

(...) uma corrente de pensamento e de ação ecológica que faz suas aquisições fundamentais do marxismo - ao mesmo tempo que se livra das suas escórias produtivistas. Para os ecossocialistas a lógica do mercado e do lucro - assim como a do autoritarismo burocrático de ferro e do "socialismo real" - são incompatíveis com as exigências de preservação do meio ambiente natural. Ainda que critiquem a ideologia das correntes dominantes do movimento operário, eles sabem que os trabalhadores e as suas organizações são uma força essencial para qualquer transformação radical do sistema, e para o estabelecimento de uma nova sociedade, socialista e ecológica. (LÖWY, 2005, pp. 47-48)

Ou seja, ao mesmo tempo que é uma corrente crítica ao economicismo que hegemonizou o marxismo e que, por conseguinte, o dogmatizou e burocratizou, trata-se de uma vertente que considera:

A questão ecológica é, a meu ver, o grande desafio para uma renovação do pensamento marxista no início do século XXI. Tal questão exige do marxismo uma revisão crítica profunda da sua concepção tradicional de "forças produtivas", bem como uma ruptura radical com a ideologia do progresso linear e com o paradigma tecnológico e econômico da civilização industrial moderna. (LÖWY, 2005, p. 43)

Sob esse aspecto, Löwy menciona que Walter Benjamin foi um dos primeiros marxistas do século XX a se colocar esse tipo de questão, pois em diversos momentos 
questionou a ideia de progresso ilimitado, o positivismo e a concepção que defendia a dominação da natureza e a necessidade de expansão das forças produtivas a qualquer custo, não observando que pela sua dinâmica expansionista, o capital põe em perigo ou destrói as suas próprias condições, a começar pelo meio ambiente natural. (LÖWY, 2005, pp. 43-44).

Desse modo, essa corrente defendida por Löwy, pretende realizar uma análise crítica da realidade partindo das lentes marxianas, mas incorporando todo o desenvolvimento que as reflexões ecológicas têm realizado no último século para interpretar e verificar os limites materiais do modelo capitalista e da civilização atual, a fim de permitir um projeto revolucionário radical e utópico que proponha uma nova civilização nos marcos de um socialismo ecológico. Nesse aspecto, menciona que:

\begin{abstract}
Essa corrente está longe de ser politicamente homogênea, mas a maioria dos seus representantes partilha de alguns temas comuns. Em ruptura com a ideologia produtivista do progresso - na sua forma capitalista e/ou burocrática - e oposta à expansão ao infinito de um modo de produção e de consumo destruidor da natureza, tal corrente representa uma tentativa original de articular ideias fundamentais do socialismo marxista com as aquisições da crítica ecológica. (LÖWY, 2005, p. 48).
\end{abstract}

A conexão entre marxismo e ecologia, portanto, buscada pela corrente ecossocialista pretende explicitar a crise civilizatória vivida pela humanidade, fruto da ordem capitalista, que põe em jogo a própria possibilidade de manutenção da vida no planeta. Sem cair em catastrofismos, pretende, também, mostrar a urgência e radicalidade de construir uma nova forma de organização socioeconômica, que rompa com a lógica do progresso imposta pela cultura do consumo e pela epistemologia positivista. Nessa senda, partimos da seguinte definição do seu projeto político:

\footnotetext{
James O'Connor define como ecossocialistas as teorias e os movimentos que aspiram a subordinar o valor de troca ao valor de uso, organizando a produção em função das necessidades sociais e das exigências de proteção do meio ambiente. O seu objetivo, um socialismo ecológico, seria uma sociedade ecologicamente racional fundada no controle democrático, na igualdade social, e na predominância do valor de uso. Eu acrescentaria que tal sociedade supõe a propriedade coletiva dos meios de produção, um planejamento democrático que permita à sociedade definir os objetivos da produção e os investimentos, e uma nova estrutura tecnológica das forças produtivas. (LÖWY, 2005, p. 49)
}

Outro aspecto fundamental da proposta ecossocialista consiste numa crítica ferrenha ao modo de produção e de consumo dos países "desenvolvidos", uma vez que ele se sustenta numa ilimitada acumulação do capital que necessita manter as desigualdades e a exploração entre os países do Norte e do Sul do globo, isto é, o "american way of life" jamais poderiam ser expandido para toda a população mundial, 
sob pena de simplesmente extinguir a humanidade em alguns dias.

Tal aspecto, contudo, jamais é visto como uma prova da necessidade que o sistema capitalista tem de manter os países da nossa região no paradigma da dependência e subdesenvolvimento tão bem criticado pelos pela teoria marxista da dependência ${ }^{4}$ e pelos teóricos decoloniais, em especial, do argentino Enrique Dussel, pois esse sistema é, necessariamente, fundado na manutenção e no agravamento da desigualdade gritante entre o Norte e o Sul. O projeto ecossocialista visa uma redistribuição planetária da riqueza, e um desenvolvimento em comum dos recursos, graças a um novo paradigma produtivo. (LÖWY, 2005, p. 74)

Diante disso, deve-se pensar um novo paradigma produtivo que revolucione e coletivize o controle dos meios de produção alterando completamente a sua natureza, direcionando a produção para a satisfação das necessidades básicas da população, ou seja, trata-se, portanto, de orientar a produção para a satisfação das necessidades autênticas, a começar por aquelas a que podemos chamar "bíblicas": água, comida, roupas, moradia. (LÖWY, 2005, p. 57)

Nessa perspectiva, Löwy retoma, portanto, a critica marxiana, em especial, a do Manuscritos Econômico-Filosóficos e a defesa da predominância, numa sociedade sem classes, do "ser" sobre o "ter", isto é, da realização pessoal, pelas atividades culturais, lúdicas, eróticas, esportivas, artísticas, políticas, em vez do desejo de acumulação ao infinito de bens e produtos. (LÖWY, 2005, p. 58)

Além da crítica econômica e ecológica, a perspectiva ecossocialista possui, também, uma preocupação ética, por sinal bem mais radical que a do ambientalismo liberal e de suas falsas promessas, pois defende um projeto utópico de transformação da realidade que rompe com a lógica econômica do mercado capitalista e se reconhece socialista, ou seja, o ecossocialismo defende (...) uma mudança radical de paradigma, um novo modelo de civilização, em resumo, uma transformação revolucionária. Essa revolução se refere às relações de produção - propriedade privada, a divisão do trabalho - mas também às forças produtivas. (LÖWY, 2005, p. 76).

\section{A perspectiva do giro descolonial}

Neste momento, pretendemos incluir em nossa reflexão a perspectiva do giro descolonial proposto por Enrique Dussel, pois no plano epistemológico-cultural torna-se

\footnotetext{
${ }^{4}$ Para um aprofundamento sobre o tema, ver: MARINI, Ruy Mauro. Subdesenvolvimento e Revolução. $4^{\mathrm{a}}$ ed. Florianópolis: Insular, 2013.
}

Em Debat: Rev. Dig., ISSNe 1980-3532, Florianópolis, n. 9, p. 56-73, jan-jun, 2013. 
indispensável superar os limites dos marcos eurocêntricos para poder compreender as lutas e reivindicações dos movimentos sociais que iremos estudar a seguir.

Pois bem, para iniciar essa temática necessitamos ter em mente a relação umbilical entre modernidade - colonialidade e a formação capitalista nos países subalternos. Essa relação constituinte do sistema capitalista atual, tem como premissa, portanto, o reconhecimento de que racismo é um eixo estrutural da nossa ordem social. Sendo que, no plano histórico-cultural, sobretudo, nos países latino-americanos e africanos significou o genocídio físico, material e espiritual de uma diversidade de cosmovisões e modelos de organização alternativos ao vigente na atualidade e, principalmente, direta e indiretamente o extermínio de milhões de seres humanos.

No plano econômico, significou o saque incansável das nossas riquezas naturais através da exploração do trabalho, seja escravocrata e/ou servil de grandes massas populacionais subjugadas aos interesses de uma pequena casta de proprietários. Permitiu, também, o processo de acumulação primitiva do capital, na qual a exploração, em especial, de minérios e matérias primas sustentou a formação dos países "desenvolvidos" anglo-americanos e parte dos países europeus.

Partindo dessa premissa, a proposta descolonial entende como marco histórico dessa nova época (modernidade) a chegada à América, "des-coberta" que "en-cobriu" a cultura e existência dos "Outros" aqui presentes, os quais foram genericamente denominados de Índios e aniquilados violentamente pelo sanguinário lucro das metrópoles. A partir desse momento, segundo Dussel, a Europa deixa de ser periferia do mundo oriental e torna-se o "centro" global da humanidade. (Dussel, 1993, p. 15)

Nesse sentido, para além do aspecto positivo que teria a Era Moderna o giro descolonial desvela a existência de um verdadeiro "mito" que funda-se na "falácia desenvolvimentista" que gera o "eurocentrismo". Esse conceito, assume a característica de uma categoria filosófica fundamental, pois explicita uma posição ontológica que compreende o modelo de desenvolvimento que historicamente foi seguido pela Europa deve ser o modelo a ser alcançado por toda a humanidade e suas respectivas culturas (Dussel, 1993, p. 24)

No plano filosófico, tal característica pode ser observada, por exemplo, em dois dos pilares da ilustração filosófica; Kant e Hegel. Ambos, a sua maneira e com as respectivas diferenças, explicitam claramente a perspectiva eurocêntrica plasmada na modernidade, bem como seu racismo inerente, o qual destruiu violentamente a riqueza e diversidade sociocultural dos povos de suas colônias e a vasta gama de riquezas naturais 
aqui existentes. Portanto, deve-se explicitar o "mito moderno", a fim de visualizar a face oculta da modernidade, qual seja, a irracionalidade da sua violência constitutiva para com as demais culturas. (Dussel, 1993, p. 24)

Descoberto o "mito moderno", outra categoria deve ser observado, nos referimos à ideia de "Colonização do mundo da vida", inserida e vista a partir do violento e sanguinário processo histórico de conquista da famigerada civilização ocidental europeia. Sobre isso, o seguinte trecho é esclarecedor:

Colonização (Kolonisierung) do mundo da vida (Lebenswelt) não é aqui uma metáfora. A palavra tem o sentido forte, histórico, real; (...) Era uma figura econômico-política. A América latina foi a primeira colônia da Europa Moderna (...)A colonização da vida cotidiana do índio, do escravo africano pouco depois, foi o primeiro processo "europeu" de "modernização", de civilização, de "subsumir" (ou alienar) o Outro como "si-mesmo";mas agora não mais como objeto de uma práxis guerreira, de violência pura - como no caso de Cortês contra os exercitos astecas ou de Pizarro contra os Incas -, e sim de uma práxis erótica, pedagógica, cultural, política econômica, quer dizer de domínio dos corpos pelo machismo sexual, da cultura, de tipos de trabalho, de instituições criadas por uma nova burocracia política, etc.. dominação do Outro. É o começo da domesticação, estruturação, colonização do "modo" como aquelas pessoas viviam e reproduziam sua vida humana. (Dussel, 1993, pp. 50-51)

A partir do resgate histórico do processo civilizatório, marcado, principalmente, por uma colonialidade expropriatória, implantado pelas metrópoles europeias na América Latina, o qual serviu de "motor" para o desenvolvimento econômico-político do sistema capitalista - torna-se indispensável repensar e interpretar esses processos a partir do contexto e da história latino-americana.

Para isso, ao contrário do discurso hegemônico, que tende a mimetizar a linearidade histórica da teoria jurídica liberal-conservadora e a sua visão estatalista da ampliação de direitos, entendemos que dois elementos são cruciais para um salto qualitativo no debate e nas reflexões sobre a atuação dos movimentos sociais latinoamericanos na sua luta insurgente por direitos, são eles: a "Descolonização" e a "Interculturalidade".

O primeiro, como referimos anteriormente, seria a necessária superação do “eurocentrismo" e da "falácia desenvolvimentista", os quais tem servido há mais de 500 anos para encobrir, por trás do lado emancipador da Modernidade, o mito sacrifical, violento e opressor do chamado: “processo civilizatório". (DUSSEL, 1993).

Em busca disso, antes de mais nada, é necessário superar a crença de que os modelos produzidos no Norte global são universais e adequados à nossa realidade e, assim, passar a construir alternativas a partir da história, dos saberes e das lutas 
promovidas pelo e no Sul global, o qual deve ser compreendido da seguinte forma:

"Sur global no es entonces un concepto geográfico, aun cuando la gran mayoría de estas poblaciones vive en países del hemisferio Sur. Es más bien una metáfora del sufrimiento humano causado por el capitalismo y el colonialismo a escala global y de la resistencia para superarlo o minimizarlo. Es por eso un Sur anticapitalista, anticolonial y antiimperialista". (Santos, 2010, p. 43)

Por isso, a descolonização é crucial para a interpretação dos processos jurídicopolíticos ocorridos na nossa região. Essa nova lente hermenêutica, portanto, é uma questão candente que deve ser suscitada por aqueles que buscam realizar pesquisas no campo do direito, da política e da sociologia de forma engajada na luta contrahegemônica ao sistema capitalista.

Enfim, chegamos ao segundo "elemento crucial" que deve ser incorporado ao debate, isto é, a Interculturalidade. Mas para isso, antes de qualquer coisa, parece importante definir o que se entende por Cultura:

\begin{abstract}
"Desde uma leitura cuidadosa e arqueológica de Marx (desde suas obras juvenis de 1835 a 1882), indicávamos que toda cultura é um modo ou um sistema de 'tipos de trabalho'. Não em vão a 'agri-cultura' era estritamente o 'trabalho da terra' - já que a 'cultura' vem etimologicamente em latim de 'cultus', em seu sentido de consagração sagrada. A poiética material (fruto físico do trabalho) e mítica (criação simbólica) são pro-dução cultural (um por fora, objetivamente, o subjetivo, ou melhor, intersubjetivo, comunitário). Desse modo o econômico (sem cair no economicismo) era resgatado". (DUSSEL, 2004, pp. 173-174)
\end{abstract}

Ou seja, ao contrário de boa parte das correntes culturalistas e pós-modernas, entendemos que a dimensão econômica é constitutiva da dimensão cultural, não há como entender uma cultura, sem entender a sua economia-política. Isso, por outro lado, também não leva ao economicismo, que reduz todos os problemas à dimensão econômica. Outro aspecto, que também deve ser esclarecido sobre o entendimento adotado de "Cultura" é o fato de não se deve partir de uma visão essencialista e homogeneizadora dos fatores culturais, uma vez que:

Culturas são "horizontes históricos de compreensão e ação que devem ser concretizados, no dia a dia, por seres humanos concretos, os quais não interpretam unitariamente nem traduzem uniformemente aquilo que em cada caso nomeiam a sua própria cultura. Com isso também se diz que, para a dinâmica interna de uma cultura pertence não só a confirmação de sua tradição, mas também a sua modificação, portanto, a dialética de tradição e inovação. (BECKA, 2010, p. 38 ).

Feitas essas definições preliminares sobre a definição conceitual de "Cultura", resta saber o porquê do "Inter" constitutivo do segundo elemento que se considera fundamental para o debate:

o diálogo intercultural necessita acima de tudo de paciência: no encontro

Em Debat: Rev. Dig., ISSNe 1980-3532, Florianópolis, n. 9, p. 56-73, jan-jun, 2013. 
intercultural se requer suficiente tempo para perceber, entender e valorar o diverso. $\mathrm{O}$ espaço para isso designa o inter, aquele espaço aberto do encontro no qual o diverso permanece primariamente indeterminado e no qual a gente se abstém do juízo e da definição. (DUSSEL, 2004, p. 176)

Assim, será nesse espaço de diálogo intercultural, partindo de uma teoria marxiana contextual e concreta, preocupada com a historicidade cotidiana do povo pobre, índio, negro, quer dizer, uma teoria que colabore organicamente com o "bloco social dos oprimidos" que se poderá superar o paradigma jurídico-político moderno e fortalecer a construção, lenta e gradual, mas revolucionárias de modelos de organização social alternativos ao capitalismo, melhor dizendo, socialistas.

\section{As lutas índígena e campesinas como potência revolucionária de um projeto ecossocialista indoamericano}

Como mencionamos anteriormente, nos limites deste trabalho, haja vista a fase atual da pesquisa que estamos realizando apresentaríamos apenas o início de uma pesquisa bibliográfica de caráter qualitativo vinculada à essas temática. No entanto, a fim de esboçar algumas indicações sobre as teorizações realizadas, buscando trazer um mínimo de concretude, por meio de relatos de alguns acontecimentos históricos, isto é, a fim de dar início a algumas observações sobre os processos constituintes retrataremos algumas das principais lutas dos movimentos indígena e campesinos bolivianos e equatorianos, isto é, a luta pela água e a sua defesa como bem comum da humanidade, bem como a luta por reconhecimento de plurinacionalidade, como forma de ter soberania sobre seus territórios.

Nesse aspecto, cumpre recordar que os processos constituintes ocorridos na Bolívia e no Equador estão marcados pela intensificação das lutas e pautas antisistêmicas e/ou contra-hegemônicas dos movimentos sociais indígenas e camponeses desses países. Tal aspecto decorre, principalmente, da excessiva e violenta acumulação primitiva dos bens naturais e, por conseguinte, do capital, por parte de setores da burguesia nacional e dos conglomerados transnacionais, que nos últimos anos aprimoram a implementação do projeto econômico-político expropriatório neoliberal. Desse modo, as transformações levadas a cabo nos últimos anos nesses países são fruto de um elevado número de necessidades sociais insatisfeitas ao longo dos anos, decorrentes da ampliação das desigualdades sociais e de mecanismos de exclusão que propiciaram um ambiente de profunda instabilidade sociopolítica nesses países. Esses 
fatores, no entanto, não são recentes, pois materializam uma tradição política autoritária centenária típica do colonialismo, marcada pelo genocídio, aculturação e pela expropriação territorial. (MALDONADO, 2013, pp. 268-286)

Portanto, os atuais processos constituintes latino-americanos devem ser observadas no marco de uma superação de toda uma tradição jurídico-política colonial historicamente marcada pela violência, exclusão e dominação de grupos populacionais, em especial, os povos originários dessas regiões. Diante disso, as lutas dos movimentos sociais indígenas e campesinos se constituem de um componente étnico-cultural de caráter anticapitalista, ou seja, são profundamente transformadoras, que traz à tona um verdadeiro debate civilizacional, que pode ser observado, por exemplo, na incorporação da concepção ecologicamente sustentável e solidaria de Sumak Kawsay (buen vivir) dos povos indígenas andinos, em oposição à perspectiva econômica exploratória e mercantilista de desenvolvimento, marcada pela ideia de progresso conformadora do sistema capitalista.

Las movilizaciones y rebeliones populares, especialmente desde el mundo indígena em Ecuador y Bolivia, asoman com la fragua de procesos históricos, culturales y sociales de larga data, conforman la base del Buen Vivir o sumak kawsay (kichwa) o suma qamaña (aymara). En esos países andinos estas propuestas revolucionarias cobraron fuerza em sus debates constituyentes y se plasmaron em sus contituciones, sin que por esto se cristalizen aún em políticas concretas. (ACOSTA, 2012, p. 19)

Será a partir da perspectiva do Sumak Kawsay, por exemplo, que o debate e as lutas reivindicatórias dos movimentos indígenas e campesinos sobre os bens comuns da humanidade passa a ganhar centralidade através da sistematização de uma proposta alternativa concreta ao modelo de desenvolvimento capitalista. Nos marcos das propostas dos movimentos indígenas e campesinos da Bolívia e Equador uma temática, nos parece sintetizar as teorizações que buscamos abordar neste texto: trata-se da luta desses povos por defender a Água. Isso mesmo, o líquido vital, abundante em boa parte do nosso continente, no último século tornou-se uma das "mercadorias" mais disputadas no mercado capitalista mundial, pois além de ser elementar para a sobrevivência da humanidade é indispensável para garantir os ciclos produtivos de setores cruciais, como por exemplo, a exploração do petróleo, a mineração, as hidrelétricas, etc.

Nesse sentido, ao longo da década de 90 com a implantação do neoliberalismo e sua sede expropriatória e privatizante, este bem comum foi leiloado às transnacionais, as quais estão comprando inúmeras fontes desse liquido precioso. Será exatamente contra esses processos de mercantilização e privatização da água que se insurgirão os 
movimentos sociais, seja para defender as suas fontes, seja, para reverter os processos de privatização e ou até mesmo para denunciar a sua contaminação por parte de empresas internacionais.

Seja na Bolívia com a série de revoltas populares contra a privatização da água que foram intituladas de Guerra da Água de Cochabamba, como no Equador com as inúmeras manifestações contra as contaminações provocadas pelas transnacionais petrolíferas e buscando reverter os processos de privatização em curso no país, as lutas dos movimentos sociais contra-hegemônicos pautaram a insurgência de um novo direito, isto é, o direito humano fundamental à água.

Será a partir dessas lutas concretas que na Constituinte de Montecristi se conseguiu incorporar essa outra perspectiva sobre o liquido vital, visto e reconhecido como um bem comum da humanidade, ou seja, não foi por acaso:

\begin{abstract}
Para conseguir este logro se contó com una alta participación y movilización de la sociedad. Essa presencia y esse aporte fueron sustantivos. Sin minimizar el trabajo de muchos asambleístas, cabe resaltar que la contribución de las organizaciones de la sociedad civil comprometidas desde hace muchos años com la defensa del agua, como Ecuarunari, Conaie, Foro de los Recursos Hídricos, entre outra, permitió consolidar una posición vigorosa. Sus aportes sirvieron incluso para la redacción misma de los textos constitucionales. (Acosta, 2010, pp. 14-15)
\end{abstract}

Nessa linha, dentre os diversos aspectos transformadores observados, especialmente, no processo constituinte equatoriano verificamos, por exemplo, a inédita proteção dos direitos da natureza pela incorporação constitucional da cosmovisão indígena expressa na mítica Pachamama ${ }^{5}$. No caso Boliviano, mesmo que não tenha ocorrido um reconhecimento expresso dos direito da natureza, diversos avanços legislativos podem ser observados, como por exemplo, a Ley de la Madre Tierra, a qual incorpora uma perspectiva diferente da relação entre ser humano/natureza, ou seja, que, em síntese, reconhece e garante a defesa dos bens comuns a partir dos marcos de uma ontologia distinta à da civilização ocidental.

Assim, esses processos constituintes retratam possíveis metamorfoses da tradição jurídico-política moderna, já que esta foi imposta durante o processo colonial de forma unilateral e violenta, sempre privilegiando a centralização do poder político e partindo de uma concepção jurídica monista, marcada pela necessidade de manter a exclusão de grandes setores da população, sobretudo, para manter os interesses de

\footnotetext{
${ }^{5}$ Nesse sentido, a Constituição Equatoriana afirma: “Art. 71. La Naturaleza o Pachamama, donde se reproduce y realiza la vida, tiene derecho a que se respete integralmente su existencia y El mantenimiento y regeneración de sus ciclos vitales, estructura, funciones y procesos evolutivos".
}

Em Debat: Rev. Dig., ISSNe 1980-3532, Florianópolis, n. 9, p. 56-73, jan-jun, 2013. 
determinada classe em segurança.

Nesse sentido, a confrontação da lógica monolítica homogeneizadora típica ao Estado-Nação, também, pode ser observada no reconhecimento constitucional da plurinacionalidade, única forma capaz de garantir a autodeterminação dos povos originários sobre seus territórios nos marcos das suas formas de organização sociopolítica. Contudo, o economista e ex-presidente da Constituinte de Montecristi alerta que:

La plurinacionalidad no es sólo reconocimiento pasivo a la diversidad de pueblos y nacionalidades, es fundamentalmente una declaración pública del deseo de incorporar perspectivas diferentes com relación a la sociedad y a la Naturaleza. El Estado plurinacional coloca em la agenda no solamente la soberanía nacional sino incluye también la soberanía patrimonial. Es justo reconocer que han sido los pueblos indígenas y afroecuatorianos los que em mayor medidad han evitado la apropiación y destrucción de las riquezas de la naturaleza (...) desde una tradición democrática de no tolerancia al abuso y a la corrupcción, las organizaciones que de tiempo em tiempohan salido a las callesa protestar contra los gobiernos neoliberales propusieron, y com éxito, definir el estado como plurinacional (...) El reconocimiento del Estado plurinacional es un paso importante, pero insuficiente, ahora toca contruirlo. (ACOSTA, 2009, pp. 20-21)

Nesse aspecto, entendemos que o histórico dessas lutas sociais, em especial, aquelas marcadas pela identidade étnico-cultural e a (re)definição do "controle" e "uso" dos bens comuns da humanidade promovidas pelas organizações indígenas e camponesas, ou seja, em defesa da Madre Tierra permitem vislumbrar algumas incidências das perspectivas dos movimentos sociais contra-hegemônicos gerando proposições criativas para a cultura jurídico-política latino-americana, sob o prisma de uma perspectiva crítica libertadora e insurgente que contribua na construção de um ecossocialismo indoamericano que frutificará do avanço das lutas populares.

\section{Bibliografia}

ACOSTA, Alberto. Plurinacionalidad. Democracia em la Diversidad. $1^{\text {a }}$ ed. Quito: Ediciones Abya-Yala. 2009.

Agua. Un derecho humano fundamental. $1^{\mathrm{a}}$ ed. Quito: Ediciones Abya-Yala. 2010.

Buen Vivir - Sumak Kawsay. Una oportunidad para imaginar outros mundos. $1^{\mathrm{a}}$ ed. Quito: Ediciones Abya-Yala, 2012. 
BECKA, Michelle. Interculturalidade no pensamento de Raúl Fornet-Betancourt. Trad. Benno Dischinger. São Leopoldo: Nova Harmonia, 2010

DUSSEL, Enrique. 1492: O Encobrimento do Outro; A origem do mito da modernidade: conferências de Frankfurt. Trad. Jaime A. Clasen. Petrópolis, RJ: Vozes, 1993.

DUSSEL, Enrique. Transmodernidade e Interculturalidade. Interpretação desde a filosofia da libertação, pp. 159-209. In: FORNET-BETANCOURT, RAÚL.

Interculturalidade: críticas, diálogos e perspectivas. Trad. Angela Tereza Sperb. São Leopoldo: Nova Harmonia, 2004.

LÖWY, Michael. Ecologia e Socialismo. São Paulo: Cortez, 2005.

(Org.). O Marxismo na América Latina. Trad. Claudia Schilling, Luis Carlos Borges. São Paulo: Editora Fundação Perseu Abramo, 1999.

MALDONADO, Efendy Emiliano. Pluralismo Jurídico e Novo Constitucionalismo na América Latina. Reflexões sobre os processos constituintes Boliviano e Equatoriano. In: CORREAS, Oscar e WOLKMER, Antonio Carlos (Org.). Crítica Jurídica na América Latina. Aguascalientes: CENEJUS, 2013, pp. 268-286.

MARIATÉGUI, José Carlos. Por um socialismo indo-americano: ensaios escolhidos. Seleção e Introdução de Michel Löwy; trad. Luiz Sérgio Henriques. Rio de Janeiro: Editora UFRJ, 2005.

Sete ensaios de interpretação da realidade peruana. Trad: de Felipe José Lindoso. $1^{a}$ ed. São Paulo: Expressão Popular/Clacso, 2008.

SANTOS, Boaventura de Sousa. Refundación del Estado en América Latina. Perspectivas desde una epistemología del Sur. Lima: Instituto Internacional de Derecho y Sociedad, 2010. 